\title{
A MINI-OVERVIEW OF VITAMIN E
}

\section{By}

TOSSON A. MORSY ${ }^{1 *}$ and ABDULLAH D. ALANAZI ${ }^{2 *}$

Faculty of Medicine, Ain Shams University, Cairo 11566, Egypt ${ }^{1}$ and Department of Biological Science and Humanities, Shaqa University, P.O. Box 1040, Ad-Dawadimi 11911, Saudi Arabia $^{2}$ ( ${ }^{*}$ Correspondence: tossonmorsy@ med.asu.edu.eg or morsy egypt 2014@gmail.com, orcid.org/0000-0003-2799-2049 \& **aalanazi@su.edu.sa)

\section{Abstract}

Vitamin E (tocopherol) is a fat-soluble vitamin with antioxidant properties; it protects cell membranes from oxidation and destruction, found in a variety of foods including oils, meat, eggs, and leafy vegetables. Their serums levels are strongly influenced by concentration of serum lipids, and do not accurately reflect tissue vitamin levels. Effective vitamin E levels are calculated as the ratio of serum alpha-tocopherol per gram total lipids.

Absorption of dietary vitamin E requires effective pancreatic exocrine function and fat absorption, unless provided in a synthetic water-soluble form. Also, a specific protein (alphatocopherol transfer protein) is required for effective transport and use. Signs and symptoms of vitamin E deficiency include hemolysis, neuromuscular disorders, ataxia, and peripheral neuropathy. Because of an abundance of tocopherols in the human diet, its deficiency is rare except in individuals with pancreatic insufficiency or other conditions causing substantial fat malabsorption, or protein-energy malnutrition and may be caused by rare genetic defects affecting vitamin $\mathrm{E}$ metabolism or transport. No syndrome of acute vitamin $\mathrm{E}$ toxicity has been described. In premature infants, high-dose vitamin $\mathrm{E}$ treatment was associated with increased risk for sepsis. Chronic intake of supplements in excess of $400 \mathrm{IU}$ daily has been associated with increased risk of hemorrhage and all-cause mortality.

Key words: Vitamin E, Action, Requirements, Deficiency, Toxicity, Therapeutic role

\section{Introduction}

Vitamins are a number of chemically unrelated families of organic substances that cannot be synthesized by humans but need to be ingested in the diet in small quantities to prevent metabolism disorders. They are divided into water-soluble and fat-soluble vitamins (Tab. 1).

Evans and Bishop (1922) discovered a substance that was deficient in rats fed a diet that contained lard and that resulted in infertility (Traber, 2000). The deficiency was corrected when a lipid extract of cereals was added to the diet; this was termed the "antisterility factor" (Evans, 1963). In 1925, vitamin E was officially recognized as the fifth vitamin. A few years later the name tocopherol from the Greek word of "toc" (child) and "phero" (to bring forth) was coined to describe its role as an essential dietary substance in normal fetal and childhood development. In 1969, the FDA formally recognized vitamin $\mathrm{E}$ as an essential nutrient for humans. Vitamin $\mathrm{E}$ is a fat-soluble com- pound and an antioxidant and protects cell membranes from oxidation and destruction (Mason, 1980). It is the collective term for four tocopherols $(\alpha-, \beta$-, $\gamma$-, and $\delta$-tocopherols) and four tocotrienols $(\alpha-, \beta-, \gamma-, \& \delta$-to cotrienols) found in food, with antioxidant activities, but cannot be interconverted, and only $\alpha$-tocopherol meets the human vitamin E requirement (Traber, 2007).

\section{Review and Discussion}

Sources: Vitamin E is found in a variety of foods including oils, meat, eggs, and leafy vegetables. Its major dietary sources are vegetable oils and nuts as well as soybean, sunflower, corn, walnut, cottonseed, palm, and wheat germ oils contain relatively higher amounts (more than 50mg vitamin E/100g oil) of vitamin $\mathrm{E}$ than other oils (Sheppard et al, 1980).

Chemistry: There are a number of biologically active vitamin $\mathrm{E}$ compounds in nature. Approximately eight naturally occurring vitamin E compounds were described, including alpha-, beta-, gamma-, and delta- tocoph- 
erol. The only forms of tocopherol that are efficiently maintained in human plasma are four of the many isomers of $\alpha$-to-copherol (RRR-, RSR-, RRS-, \& RSS- $\alpha$-to-copherol, which are present in "all racemic" synthetic vitamin E; only the RRR-form is present in foods). These are the forms of vitamin $E$ that are most biologically active, and are the forms to which the Recommended Daily Allowances apply. Synthetic vitamin E supplements containing all the eight isomers of $\alpha$-tocopherol (All racemic) has approximately half of the activity of "natural source" vitamin E. However, all of the isomers of $\alpha$ tocopherol may contribute to the potential adverse effects of supplemental vitamin E, and are included in the calculation of an upper limit for supplementation (Huang and Appel, 2003). Gamma-tocopherol is transported less efficiently than $\alpha$-tocopherol, but is more abundant in the US diet, so similar tissue levels are achieved from dietary vitamin E. Pharmacological doses of $\alpha$-tocopherol taken in supplements reduce levels of gamma-tocopherol in plasma (Burton et al, 1983).

Actions: Vitamin E works as a free radical scavenger, protecting polyunsaturated fatty acids (PUFA), a major structural component of the cell membranes, from peroxidation. In the past few decades, there was an increasing interest in the role of free radicals and anti-oxidants in atherosclerosis and carcinogenesis (Jialal et al, 1995). Deficiency of vitamin $\mathrm{E}$ has been connected to cardiovascular events. Low-density lipoprotein (LDL) plays a central role in these hypotheses. When LDL is exposed to oxidative stress, it undergoes a cascade of changes affecting the vascular endothelium, thereby facilitating atherogenesis (Hodis et al, 1995). This theory is referred to as the oxidative modification hypothesis, and has fueled epidemiologic studies and clinical trials in cardiology to determine the role of antioxidants, such as vitamin $\mathrm{E}$, in prevention and treatment of atherosclerotic cardiovascular disease (Stampfer and Rimm, 1995). However, trials of vitamin E supplementation have generally showed no effect in heart disease prevention.

Gamma-tocopherol has unique anti-inflammatory activities, mediated by reductions in prostaglandin E2 (Jiang et al, 2000). High doses of vitamin $\mathrm{E}$ (as $\alpha$-tocopherol) reduce levels of gamma-tocopherol, perhaps explaining the adverse effects of pharmacological doses of vitamin (Rimm et al, 1993).

Some functions of vitamin $\mathrm{E}$ are independent of the antioxidant/radical scavenging activity, including inhibition of cell proliferation, platelet aggregation, and monocyte adhesion. Several other effects at the molecular level have been identified, but the clinical implications of these actions have not been established (Zingg and Azzi, 2004).

Metabolism: Like other fat-soluble vitamins, bioavailability of vitamin $\mathrm{E}$ depends upon physiologic mechanisms for fat digestion and absorption. This process requires lipolytic function of pancreatic enzymes (Traber et al, 1990). Pancreatic esterases are the enzymes responsible for breaking down the tocopheryl-ester bonds between vitamin $\mathrm{E}$ and fatty acids (Nakamura et al, 1975). Within the intestinal mucosal cells, chylomicrons are produced from phospholipids, triglycerides, apolipoproteins, and fat-soluble vitamins. Synthesis of chylomicrons is needed for transport of vitamin $\mathrm{E}$ via the liver lymphatic system (Cohn et al, 1988a). Within hepatocytes, chylomicron remnants are broken down by lysosomes, and RRR- $\alpha$ tocopherol is preferentially secreted into the bloodstream, packaged within VLDL molecules. The transport protein for $\alpha$-tocopherol is named $\alpha$-tocopherol transfer protein (ATTP) (Cohn et al, 1988b)

Requirements: Dietary vitamin E content is variable and proportional to vegetable oil intake. American diets of 2000 to $3000 \mathrm{kcal}$ /day contain 7 to $10 \mathrm{mg}$ of $\alpha$-tocopherol equivalents. However, this is likely an underestimate because dietary fat intake is commonly under-reported.

Healthy population: The United States National Academy of Sciences Food and Nutri- 
tion Board recommended $15 \mathrm{mg}$ of dietary $\alpha$ tocopherol units per day for adolescents and adult men and women. This is the equivalent of 22 International Units (IU) of "naturalsource" vitamin E (RRR- $\alpha$-tocopherol), or 33 IUs of the synthetic form (all-rac-alphatocopherol). In children, the recommended daily allowance rises from $6 \mathrm{mg}$ at 1 to 3 years of age to $15 \mathrm{mg}$ by 14 to 18 years. Although the requirements are stated in terms of $\alpha$-tocopherol equivalents, a substantial portion, which provided as gamma-tocopherol if dietary sources are used. So, dietary vitamin $\mathrm{E}$ has advantages over vitamin $\mathrm{E}$ taken as a supplement (Yoshida et al, 1992).

Cholestatic disease: Patients with cholestasis or pancreatic exocrine insufficiency are at risk for vitamin E deficiency because of malabsorption of fat and fat-soluble vitamins. The patients with cholestasis also tend to have hyperlipidemia, which strongly influences vitamin E levels, so assessment of their vitamin $\mathrm{E}$ status requires simultaneous measurement of alpha-tocopherol and serum lipids (Traber et al 1986). If vitamin E deficiency is diagnosed, these patients are treated with large oral doses of vitamin E. Watermiscible vitamin $\mathrm{E}$ (d- $\alpha$-tocopherol glycol 1000 succinate, TPGS) is most effective in these patients. However, water-miscible preparations have not been shown to be superior for patients with cystic fibrosis who are taking concurrent pancreatic enzyme supplements (Soltani-Frisk et al, 2001).

Typical supplementation regimens for infants and children with cholestasis are 25 to 50 int. units $/ \mathrm{kg} /$ day of vitamin E ( $\alpha$-tocopherol), or 15 to 25 int. units $/ \mathrm{kg} /$ day of watermiscible vitamin E (Feranchak and Sokol, 2007).

The prevalence of vitamin E deficiency in adults with cholesteric liver diseases has not been well defined. It is probably most common in patients with severe and prolonged primary biliary cirrhosis, in who estimates of vitamin E deficiency range from 10 to $50 \%$ (Muñoz et al, 1989). For patients with significant cholestasis (e.g., bilirubin $>2.0 \mathrm{mg}$ /
$\mathrm{dL}$ ), routine monitoring of vitamin E levels is recommended, with vitamin E replacement as needed (Lindor et al, 2012).

Deficiency: Vitamin E deficiency is uncommon in humans except in unusual circumstances due to the abundance of tocopherols in the diet. Individuals eating a vegetarian or vegan diet typically are not at increased risk for vitamin $\mathrm{E}$ deficiency. Individuals with fat malabsorption and steatorrhea are at risk for deficiency of all lipidsoluble vitamins (Farrell, 1980). These included cirrhosis, cholesteric liver disease, cystic fibrosis, small bowel bacterial overgrowth, and pancreatic insufficiency, celiac disease, and Crohn disease. Deficiency degree is generally proportional to magnitude and steatorrhea duration (Sokol et al, 1983).

There are also several genetic disorders that lead to vitamin E deficiency. As an example, a genetic defect in the A-TTP ( $\alpha$-tocopherol transfer protein) is associated with neurologic deficits and is known as ataxia with vitamin E deficiency (AVED). Affected patients have symptoms similar to Friedreich's ataxia (Ben Hamida et al, 1993). These patients sometimes respond to oral supplementation of vitamin $\mathrm{E}$ in doses of 800 to $1200 \mathrm{mg} / \mathrm{day}$. More often, supplementation serves to prevent the disease progression (Sokol, 1993).

In adults and children, vitamin E deficiency can cause neuromuscular disorders and hemolysis. Low serum levels of vitamin $\mathrm{E}$ (defined as below $0.5 \mathrm{mg} / \mathrm{dL}$ ) may cause no appreciable symptoms, or may manifest as subtle neurologic abnormalities. Neuromuscular disorders associated with vitamin $\mathrm{E}$ deficiency are mostly of the neuropathic and myopathic type (Kumar, 2007). The neuropathy generally consists of a spinocerebellar syndrome, with variable involvement of the peripheral nerves. Clinical manifestations were ataxia, hyporeflexia, and loss of proprioceptive and vibratory sensation (Oski and Barness, 1967). A skeletal myopathy and pigmented retinopathy also might be present (Natta and Machlin, 1972). 
Vitamin E deficiency can shorten the lifespan of red blood cells. In premature infants, vitamin E deficiency may cause a hemolytic anemia (Ray et al, 2007). Congenital hemolytic disorders such as thalassemia, sickle cell anemia, glucose-6-phosphate dehydrogenase deficiency (G-6-PD), and spherocytosis may be associated with low vitamin $\mathrm{E}$ plasma levels, likely because of increased oxidant stress and antioxidant consumption (Walter et al, 2006). Oral therapy with vitamin E supplementation may be of benefit, but efficacy was not proved (Rachmilewitz et al, 1979).

Excess and toxicity: The long-term effects and the safety of vitamin E supplementation are unclear. Most studies suggest that doses of vitamin $\mathrm{E}$ supplementation in doses of 100 to 400 IU per day are safe for most patients (Hathcock, 1997). But, other reports caution against the use of higher doses. One study, for example, found a higher evidence of mortality due to hemorrhagic strokes in vitamin E supplementation. Others were caution against the vitamin $\mathrm{E}$ use in patients with an increased propensity to bleeding or on oral anticoagulants as warfarin (Jaja et al, 2005). Animal models have showed impaired absorption of fat-soluble vitamins A \& $\mathrm{K}$ with large vitamin $\mathrm{E}$ supplements. Large oral supplements of vitamin $\mathrm{E}$ were associated with necrotizing enterocolitis in infants. Vitamin E may impair the hematologic response to iron in children with iron-deficiency anemia (Finer et al, 1984).

A meta-analysis examined dose-response relationship between the vitamin $\mathrm{E}$ and overall mortality in a total of 19 randomized clinical trials that included a total of 135,967 participants. Doses of vitamin $\mathrm{E}$ ranged from 16.5 to $2000 \mathrm{IU} /$ day (median, $400 \mathrm{IU})$. Vitamin E supplementation with a dose $\geq 400$ IU/ day was associated with a significantly increased risk of all-cause mortality (95\% CI 374 per 10,000 persons). Thus, the patients without special indications should not take vitamin E supplements for the prevention of disease (Miller et al, 2005).
Therapeutic Actions: Typical dosing of vitamin $\mathrm{E}$ is given in terms of $\alpha$-tocopherol ( $15 \mathrm{mg}$ of $\alpha$-tocopherol $=22$ IU of natural vitamin E or 33 IU of synthetic vitamin E).

1- Cancer: Various effects of vitamin $E$ were reported on certain cancers, particularly within subgroups such as smokers (Kirsh et al, 2006), but randomized trials did not support a protective effect. Randomized trials of vitamin $\mathrm{E}$ in cancer prevention include: Women's Health Study followed 39,876 apparently healthy women ages 45 and older for a mean of 10.1 years (Lee et al, 2005). Compared with placebo, supplementation with 600 IU of natural-source vitamin E on alternate days had no effect on the incidence of all cancer (relative risk (RR 1.01, 95\% CI 0.94-1.08) or on breast cancer (RR 1.00), lung cancer (RR 1.09), colon cancer (RR 1.00), or cancer death (RR 1.12). The Polyp Prevention Study observed no reduction in colorectal polyps among subjects randomized to receive vitamin $\mathrm{E}$ (Greenberg et al, 1994). The HOPE-TOO trial found no effect of vitamin E supplementation (400IU daily) on cancer incidence nor cancer deaths after a median follow-up of seven years (Lonn et $a l$, 2005). An analysis of 7627 women who were free of cancer at random assignment in the Women's Antioxidant Cardiovascular Study did not find effect of vitamin E (600IU every other day) on the cancer incidence after a mean follow-up of 9.4 years (Lin et al, 2009). In contrast to these negative trials, the ATBC Cancer Prevention Study observed a $32 \%$ decrease in prostate cancer incidence \& $41 \%$ decrease in prostate cancer mortality among men randomized to $50 \mathrm{mg}$ (75 IU) of $\alpha$-tocopherol (vitamin E) for five to eight years compared with placebo (Heinonen et al, 1994).

However, subsequent large randomized trials found no reduction in prostate cancer incidence with vitamin E supplementation: The select trial followed 35,533 men (ages 50 and older for African American men and ages 55 and older for other men) for a median of 5.5 years. Compared with placebo, vit- 
amin E supplementation (400 IU daily) had no effect on rates of prostate cancer (hazard ratio [HR] $1.13,95 \%$ CI $0.95-1.35$ ) or total cancer (HR 1.03, CI 0.91-1.17). The Physicians' Health Study II followed 14,641 male physicians ages 50 and older for an average of 8.0 years (Lippman et al, 2009). Compared with placebo, vitamin E supplementation (400IU every other day) had no effect on the prostate cancer incidence (HR 0.97, CI 0.85-1.09) or total cancer (HR 1.04, CI 0.95-1.13). Supplementation with vitamin $\mathrm{E}$ does not appear to be beneficial in preventing cancer, but Peh et al. (2016) concluded that with the concerted efforts in synthesizing novel vitamin $\mathrm{E}$ analogs and clinical pharmacology of vitamin E, it was likely that certain vitamin $\mathrm{E}$ isoform( $\mathrm{s}$ ) could be therapeutic agents against human diseases besides cancer. Kaidar-Person et al. (2018) reported that the use of pentoxifylline \& vitamin E of treatment or prevention of radiation-induced fibrosis in breast cancer patients and that this regimen may reduce RT-associated toxicity.

2- Dermatology, Vitamin E is an important fat-soluble antioxidant used for more than 50 years in dermatology. It is an important ingredient in many cosmetic products, protects the skin from various deleterious effects due to solar radiation by acting as a free-radical scavenger. Experimental studies showed that vitamin $\mathrm{E}$ has anti-tumorigenic and photoprotective properties, with a paucity of controlled clinical studies providing a rationale for well-defined dosages and clinical indications of vitamin E usage in dermatological practice (Keen and Hassan, 2016).

3- Cardiovascular disease: Nearly all randomized trials of vitamin $\mathrm{E}$ did not show any benefit for primary or secondary prevention of CHD (Vivekananthan et al, 2003). Also, vitamin E supplementation may increase the risk of heart failure (Lonn et al, 2005). Wa$\mathrm{ng}$ and $\mathrm{Xu}$ (2019) added that higher vitamin E may increase the risk of $\mathrm{CAD} / \mathrm{MI}$ and safety and efficacy of vitamin E supplementation use should be reevaluated. Fan et al. (2019) found that genetically elevated vita- min E was associated with increased risk of coronary artery disease, suggested an adverse causality between circulating vitamin $\mathrm{E}$ and coronary artery disease.

4- Stroke: The evidence did not suggest that vitamin E supplements protect against stroke. Ascherio et al. (1999) in an observational study including 43,738 men, showed no association between supplemental vitamin $\mathrm{E}$ (250 IU or more daily) and stroke risk. In the randomized ATBC study, which followed 22,271 male smokers for a median of six years, vitamin E supplementation $50 \mathrm{mg}$ (75 IU) had no overall effect on stroke risk. However, in a subgroup analysis, vitamin E increased the risk for subarachnoid hemorrhage and decreased the risk for ischemic stroke particularly in men with hypertension (Leppala et al, 2000). Lonn et al. (2001) in a study of 732 high-risk patients from HOPE trial, supplementation with vitamin $\mathrm{E}$ had no effect on progression of carotid intimal medial thickness over an average follow-up of 4.5 years. However, Salonen et al. (2003) in a six-year randomized trial of daily supplementation with vitamin E (136 IU) and vitamin C (250mg slow release) in 520 people showed a significant improvement in the average annual increase in carotid artery intima-media thickness compared with placebo $(.010 \mathrm{~mm}$ vs. $.014 \mathrm{~mm})$, and clinical implications were unclear. Cheng et al. (2018) from observational studies on associations between vitamin $\mathrm{E}$ intake \& stroke risk remain controversial, they concluded the meta-analysis provides evidence that a higher dietary vitamin $E$ intake is associated with a lower stroke risk.

5- Dementia: Although observational studies suggested that increased dietary intake of vitamin $\mathrm{E}$ or vitamin $\mathrm{E}$ supplementation might protect against the development of Alzheimer disease and vascular dementia (Engelhart et al, 2002), in randomized trials vitamin E supplementation did not appear to affect the risk of dementia (Kang et al, 2006). Farina et al. (2017) found no evidence that the $\alpha$-tocopherol form of vitamin E given to 
people with MCI prevents progression to dementia, or that it improves cognitive function in people with MCI or dementia due to $\mathrm{AD}$, but, a moderate quality evidence from a single study that it may slow functional decline in AD. Gugliandolo et al. (2017) in animal models found that high vitamin $\mathrm{E}$ doses and prolonged supplementation seemed to be associated with better Alzheimer results. They added that a higher intake of foods rich in vitamin $E$, which contain a combination of different forms, was associated with a better cognitive function, but clear results about vitamin E efficacy in AD required.

6- Infection: Studies have reported that supplementation with vitamin E improved the immune response (Serafini, 2000). Such an effect is of particular interest in elderly people, in whom an age-related decline in immune response may increase the risk of infections and their complications. But, clinical trials that have examined the use of vitamin $\mathrm{E}$ to prevent infections in the elderly have not found clinical benefits. Large, randomized, placebo-controlled studies did notfind reduction in the incidence of respiratory infections when either institutionalized (Meydani et al, 2004) or non-institutionalized elderly patients received daily vitamin E supplements experienced a respiratory infection, those who received vitamin E (200IU/day) had a significantly longer total illness duration (19 vs. 14 days), more symptoms, and a higher frequency of fever and activity restriction (Graat et al, 2002). Meydani et al. (2018) suggested that on the basis of mechanistic studies showed that biological plausibility, correction of a major cellular dysfunction in older adults, and strong evidence from several animal and a few human studies indicating a reduction in risk and morbidity from infections. Cordero et al. (2018) reported that the potential complementary use of vitamin E to ameliorate sensory and autonomic dysfunctions associated with spinal cord injury, and identified promising newcellular and functional targets of its neuro- protective effects.

7- Viral infection: Influenza is an acute infectious disease that exerts a very great effect on human society, causing huge medical and economic losses. Influenza usually occurs in annual seasonal (winter) outbreaks or epidemics (in moderate temperature climates). Moreover, influenza pandemics periodically attack the populations of all continents. People of all ages are affected, but the prevalence is greatest in school-age children. The disease's severe course, complications, and mortality were greatest in infants, elderly, and those with underlying illnesses-chronic pulmonary or cardiovascular diseases, and diabetes mellitus. The severe complications include hemorrhagic bronchitis or pneumonia (primary viral or secondary bacterial). Besides, fulminant fatal influenza viral pneumonia can occur, with death proceeding in as little as 48 hours after the initial flu symptoms (WHO, 2010). The pathogenesis of influenza virus infection is associated with two general processes in the human body: (i) local lung damage due to viral replication in the columnar ciliary epithelium of bronchi and bronchioles, which led to progressive damage of the alveolar cells, bronchopneumonia (viral or combined viral-bacterial), massive bronchitis (including bronchiolitis), and the like, as the major causes of death (Taubenberger and Morens, 2008), (ii) a dramatic inflammatory burst that induces among other processes an increase in reactive oxygen species generation, causing extensive damage in cellular membranes, predominantly in the small vessels, arterioles, and capillaries (Berrri et al, 2013). Besides, extra-pulmonary complications affect many organs and tissues, as heart, brain, middle ear, liver, and endocrines, even stomach and kidneys, though was rare (Papic et al, 2012). Among the antioxidants tested in influenza virus infections in mice, vitamin E occupies the leading position because of its efficacy in preventing oxidative damage via its free-radical scavenging activity. Although vitamin $\mathrm{E}$ is not possessing specific antiviral action, its antioxi- 
dant effect probably plays important role in lung and liver protection. Attention should be paid to the synergistic character of antiviral effect of the combination vitamin $\mathrm{E}$ and oseltamivir. Vitamin E could be recommended as a component in multitarget influenza therapy (Mileva and Galabov, 2018). 8- Venous thromboembolism: Vitamin E high doses may interfere with vitamin $\mathrm{K}$ and affect the coagulation. A secondary analysis from the Women's Health Study found that women randomly assigned to receive $600 \mathrm{IU}$ vitamin E every other day had a lower risk of venous thromboembolism (VTE) than in women received placebo with hazard ratio $0.79,95 \%$ CI $0.66-0.94$ (Glynn et al, 2007). Lutsey (2012) reported that the evidence suggested a relation between dietary intake and the vitamin E risk was relatively weak overall. Gan et al. (2017) highlighted lack of inhibitory effect on platelet aggregation after short-term supplementation of PTT mixture in participants with metabolic syndrome. Other non-antioxidant functions of vitamin E were also presented, as its anti-inflammatory effects, role in prevention of cardio-vascular diseases and cancer, as well as protective functions against neurodegenerative and other diseases (Szymańska et al, 2017).

Because of concerns about raised risks of bleeding, the Institute of Medicine recommends a Tolerable Upper Intake Level (UL) for vitamin $\mathrm{E}$ consumption from supplements. Recommended upper limit is $1000 \mathrm{mg}$ of $\alpha$-tocopherol daily (approximately 1,500 IU of natural source or 1,100 IU of synthetic vitamin E) for adults without fat malabsorption or other cause of vitamin E malabsorption. The UL in children rises from $200 \mathrm{mg} /$ day at 1 to 3 years to $600 \mathrm{mg}$ daily at 9 to 13 years. Because of increasing evidence showed adverse effects of pharmacologic vitamin $\mathrm{E}$ doses, it is possible that this UL is too high and not recommend supplementation near this level except when indicated to correct deficiency (Bjelakovic et al, 2012).

Therapeutic Actions: The benefit of vitamin E supplementation on cancer, cardiovasc- ular disease, stroke, dementia, and liver diseases (such as nonalcoholic fatty liver disease) continue to be evaluated. A benefit of supplementation in cardiovascular disease appeared to be unlikely.

In premature infants, hemolytic anemia is a common abnormality encountered in the presence of vitamin E deficiency. Vitamin E therapy slightly increases hemoglobin concentrations and reduces the incidence of periventricular hemorrhage (Brion et al, 2003). However, the risk of sepsis also was increased with high-dose supplementation, regardless of whether administered by intravenous or oral routes. A few studies suggest some benefit in preventing retinopathy of prematurity, but overall the evidence is inconclusive (Tasman et al, 2006).

Association between development of Alzheimer disease and vitamin E deficiency was suggested (Grundman, 2000). But, randomized trials suggest that vitamin E supplementation does not affect the risk of cognitive impairment or dementia, but a possible role in slowing progression of Alzheimer disease (Tabet and Birks, 2000). Although controversial, few studies support potential benefits of vitamin E supplementation in treating cataracts and/or age-related macular degeneration (Evans, 2006). A study suggested benefit in preventing or treating tardive dyskinesia (Lohr, and Caligiuri 1996). A meta-analysis concluded that it may protect against deterioration of tardive dyskinesia, but probably did not improve symptoms (Soares and McGrath, 2001).

Serum vitamin E levels are strongly influenced by concentration of serum lipids, and not accurately reflect tissue vitamin levels (Bieri et al, 1983). Thus, effective vitamin $\mathrm{E}$ levels are calculated as the following ratio: Effective serum vitamin E level $=\alpha$-tocopherol/ (cholesterol + triglycerides). A normal ratio is $>0.8 \mathrm{mg} \alpha$-tocopherol/gm total lipids. For patients with normal serum lipids levels, serum $\alpha$-tocopherol levels provide an adequate estimate of vitamin $\mathrm{E}$ sufficiency. $\alpha$-tocopherol levels of less than $0.5 \mathrm{mg} / \mathrm{dL}$ or 
$5 \mu \mathrm{g} / \mathrm{mL}$, or $11.5 \mu \mathrm{mol} / \mathrm{L}$ are considered deficient. In a USA national survey, the $5^{\text {th }}$ percentile for vitamin $\mathrm{E}$ serum levels was 0.62 $\mathrm{mg} / \mathrm{dL}$ or $14.3 \mu \mathrm{mol} / \mathrm{L}$, and the $25^{\text {th }}$ percentile was $0.79 \mathrm{mg} / \mathrm{dL}$ or $18.5 \mu \mathrm{mol} / \mathrm{L}$ (Trevithick et al, 1993).

\section{Recommendations}

Patients without special indications must avoid taking daily supplements containing high doses ( $>400$ IU) of vitamin E (Grade 2B). Individuals with severe pancreatic insufficiency or cholesteric liver disease may have vitamin E deficiency due to fat malabsorption. For such patients, vitamin E supplementation was recommended (Grade $1 \mathrm{~A}$ ). Doses of about 25 to $50 \mathrm{int}$. units $/ \mathrm{kg} /$ day are generally effective in children. Alternatively, water miscible vitamin $\mathrm{E}$ can be used to maximize absorption, at a dose of 15 to 25 int. units $/ \mathrm{kg} /$ day.

Vitamin E supplementation does not support in prevention or treatment of cancers, cardiovascular and cerebrovascular disease, dementia, and retinopathy of prematurity. Weak evidence suggests a possible role in slowing the progression of Alzheimer disease, tardive dyskinesia, and macular degeneration. In premature infants, vitamin E supplementation may reduce the risk of periventricular hemorrhage, but also increases the risk of sepsis. It does not improve outcomes in healthy children or adults. High-dose supplementation may increase mortality and the risk of hemorrhage.

\section{References}

Ascherio, A, Rimm, EB, Hernan, MA, et al, 1999: Relation of consumption of vitamin E, vitamin $\mathrm{C}$, and carotenoids to risk for stroke among men in the United States. Ann. Intern. Med. 130: 963-6.

Ben Hamida, M, Belal, S, Sirugo, G, et al, 1993: Friedreich's ataxia phenotype not linked to chromo- some 9 and associated with selective autosomal recessive vitamin E deficiency in two inbred Tunisian Families. Neurology 43:2179.

Berrri, F, Le, VB, Jandrot-Perrus, M. Lina, B, Riteau, B, 2013: Switch from protective to adverse inflammation during influenza: Viral determinants and hemostasis are caught as culprits. Cell. Mol. Life Sci. 71:885-98.
Bieri, JG, Corash, L, Hubbard, VS, 1983: Medical uses of vitamin E. N. Engl. J. Med. 308: 1063-7.

Bjelakovic, G, Nikolova, D, Gluud, LL, et al, 2012: Antioxidant supplements for prevention of mortality in healthy participants and patients with various diseases. Cochrane Database Syst. Rev. 3:CD007176.

Brion, LP, Bell, EF, Raghuveer, TS, 2003: Vitamin $\mathrm{E}$ supplementation for prevention of morbidity and mortality in preterm infants. Cochrane Database Syst. Rev.:CD003665.

Burton, GW, Joyce, A, Ingold, KU, 1983: Is vitamin $\mathrm{E}$ the only lipid-soluble, chain-breaking anti-oxidant in human blood plasma and erythrocyte membranes? Arch. Biochem. Biophys. 221:281-6.

Cheng, P, Wang, L, Ning, S, Liu, Z, Lin, H, 2018: Vitamin $E$ intake and risk of stroke: a meta-analysis. Br. J. Nutr. 120, 10:1181-8

Cohn, JS, McNamara, JR, Cohn, SD, et al, 1988a: Postprandial plasma lipoprotein changes in human subjects of different ages. J. Lipid Res. 29:469-72.

Cohn, W, Loechleiter, F, Weber, F, 1988b: Alpha-tocopherol is secreted from rat liver in very low density lipoproteins. J. Lipid Res. 29: 1359-64.

Cordero, K, Coronel, GG, Serrano-Illán, M, Bracero, JC, Figueroa, JD, et al, 2018: Effects of dietary vitamin $\mathrm{E}$ supplementation in bladder function and spasticity during spinal cord injury. Brain Sci. Mar; 8(3): 38. doi: 10.3390/8030038

Engelhart, MJ, Geerlings, MI, Ruitenberg, A, et al, 2002: Dietary intake of antioxidants and risk of Alzheimer disease. JAMA 287:3223-9.

Evans JR, 2006: Antioxidant vitamin and mineral supplements for slowing the progression of age-related macular degeneration. Cochrane Database Syst. Rev.:CD000254.

Evans, HM, 1963: The pioneer history of vitamin E. Vitam. Horm. 1 20:379-82.

Fan, C, Huang, T, Kong, X, Zhang, X, Zou, Z, 2019: Circulating vitamin $E$ and cardiometabolic measures: a Mendelian randomization analysis. J. Clin. Biochem. Nutr. 65, 2:160-9

Farina, N, Llewellyn, D, Isaac, M, Tabet, N, 2017: Vitamin E for Alzheimer's dementia and mild cognitive impairment. Cochrane Database Syst. Rev. Apr 18;4:CD002854. doi:10.1002/ 14651858.

Farrell, PM, 1980: Deficiency states pharmacological effects, and nutrient requirements. In: Vi- 
tamin E: A Comprehensive Treatise, Machlin LJ (Ed.), Marcel Dekker, New York.

Feranchak, AP, Sokol, RJ, 2007: Medical and nutritional management of cholestasis in infants and children. In: Liver disease in children, $3^{\text {rd }} \mathrm{ed}$, Suchy, FJ, Sokol, RJ, Balistreri, WF (Eds.), Cambridge University Press, New York.

Finer, NN, Peters, KL, Hayek, Z, Merkel, CL, 1984: Vitamin $\mathrm{E}$ and necrotizing enterocolitis. Pediatrics 73:387-90.

Gan, YL, Fu, JY, Lai, OM, Chew, BH, Yuen, KH, et al, 2017: Effect of palm-based tocotrienols and tocopherol mixture supplementation on platelet aggregation in subjects with metabolic syndrome: A randomized controlled trial. Sci. Rep. 7: 11542

Glynn, RJ, Ridker, PM, Goldhaber, SZ, et al, 2007: Effects of random allocation to vitamin $E$ supplementation on the occurrence of venous thromboembolism: report from the women's health study. Circulation 116:1497-501.

Graat, JM, Schouten, EG, Kok, FJ, 2002: Effect of daily vitamin e and multivitamin-mineral supplementation on acute respiratory tract infections in elderly persons: A randomized controlled trial. JAMA 288:715-9.

Greenberg, ER, Baron, JA, Tosteson, TD, et al, 1994: A clinical trial of antioxidant vitamins to prevent colorectal adenoma. Polyp Prevention Study Group. N. Engl. J. Med. 331:141-8.

Grundman, M, 2000: Vitamin E and Alzheimer disease: the basis for additional clinical trials. Am. J. Clin. Nutr.71:630S.

Gugliandolo, A, Bramanti, P, Mazzon, E, 2017: Role of vitamin $E$ in the treatment of alzheimer's disease: Evidence from animal models. Int. J. Mol. Sci. 12:2504-12.

Hathcock, JN, 1997: Vitamins and minerals: Efficacy and safety. Am. J. Clin. Nutr. 66:427-30.

Heinonen, OP, Albanes, D, Virtamo, J, et al, 1998: Prostate cancer and supplementation with alpha-tocopherol and beta-carotene: Incidence and mortality in a controlled trial. J. Natl. Cancer Inst. 90:440-4.

Hodis, HN, Mack, WJ, LaBree, L, et al, 1995: Serial coronary angiographic evidence that antioxidant vitamin intake reduces progression of coronary artery atherosclerosis. JAMA 273: 1849-52.

Huang, HY, Appel, LJ, 2003: Supplementation of diets with alpha-tocopherol reduces serum concentrations of gamma- and delta-tocopherol in humans. J. Nutr. 133:3137-40.
Jaja, SI, Aigbe, PE, Gbenebitse, S, Temiye, E O, 2005: Changes in erythrocytes following supplementation with alpha-tocopherol in children suffering from sickle cell anemia. Niger Postgrad. Med. J. 12:110-5.

Jialal, I, Fuller, CJ, Huet, BA, 1995: The effect of alpha-tocopherol supplementation on LDL oxidation: A dose-response study. Arterioscler. Thromb. Vasc. Biol. 15:190-6.

Jiang, Q, Elson-Schwab, I, Courtemanche, C, Ames, BN, 2000: Gamma-tocopherol and its major metabolite, in contrast to alpha-tocopherol, inhibit cyclooxygenase activity in macrophages and epithelial cells. Proc. Natl. Acad. Sci. USA 97:11494-9.

Kaidar-Person, O, Marks, LB, Jones, EL, 2018: Pentoxifylline and vitamin $E$ for treatment or prevention of radiation-induced fibrosis in patients with breast cancer. Breast J. 24, 5:816-9 Kang, JH, Cook, N, Manson, J, et al, 2006: A randomized trial of vitamin $\mathrm{E}$ supplementation and cognitive function in women. Arch. Intern.

Med. 166:2462-6.

Keen, MA, Hassan, I, 2016: Vitamin E in dermatology. Indian Dermatol. Online J. 7, 4:311-5

Kirsh, VA, Hayes, RB, Mayne, ST, et al, 2006: Supplemental and dietary vitamin E, betacarot-ene, and vitamin $\mathrm{C}$ intakes and prostate cancer risk. J. Natl. Cancer Inst. 98:245-9.

Kumar, N, 2007: Nutritional neuropathies. Neurol. Clin. 25:209-12.

Lee, IM, Cook, NR, Gaziano, JM, et al, 2005: Vitamin $\mathrm{E}$ in the primary prevention of cardiovascular disease and cancer: the Women's Hea1th Study: a randomized controlled trial. JAMA 294:56-60.

Lindor, KD, Gershwin, ME, Poupon, R, et al, 2012: AASLD Practice Guidelines, Primary Biliary Cirrhosis. Available at: file://www.aasld.or$\mathrm{g} /$ practiceguidelines/Documents/Bookmarked $\% 2$ 0/Practice\%20Guidelines/PrimaryBillaryCirrhos is7-2009.pdf

Leppala, JM, Virtamo, J, Fogelholm, R, et al, 2000: Vitamin $E$ and beta carotene supplementaion in high risk for stroke. Arch. Neurol. 57: 1503-6.

Lin, J, Cook, NR, Albert, C, et al, 2009: Vitamins $\mathrm{C}$ and $\mathrm{E}$ and beta carotene supplementation and cancer risk: a randomized controlled trial. J. Natl. Cancer Inst. 101:14-9.

Lippman, SM, Klein, EA, Goodman, PJ, et al, 2009: Effect of selenium and Vitamin $E$ on risk of prostate cancer and other cancers: The seleni- 
um and vitamin E cancer prevention trial (SELECT). JAMA 301:39-42.

Lohr, JB, Caligiuri, MP, 1996: A double-blind placebo-controlled study of vitamin E treatment of tardive dyskinesia. J. Clin. Psychiatry 57:167. Lonn, E, Bosch, J, Yusuf, S, et al, 2005: Effects of long-term vitamin $\mathrm{E}$ supplementation on cardio-vascular events and cancer: a randomized controlled trial. JAMA 293:1338-42.

Lonn, EM, Yusuf, S, Dzavik, V, et al, 2001: Effects of ramipril and vitamin $\mathrm{E}$ on atherosclerosis. The study to evaluate carotid and ultrasound changes in patients treated with ramipril and vitamin E (SECURE). Circulation 103:919-23. Lutsey, PL, 2012: Invited Commentary: Diet and risk of venous thromboembolism, a hard nut to crack. Am. J. Epidemiol. 175, 2:127-30.

Mason, KE, 1980: The first two decades of vitamin E history. In: Vitamin E: A Comprehensive Treatise, Machlin, LJ (Eds), Marcel Dekker, New York.

Meydani, SN, Leka, LS, Fine, BC, et al, 2004: Vitamin $\mathrm{E}$ and respiratory tract infections in elderly nursing home residents: A randomized controlled trial. JAMA 292:828-30.

Meydani, SN, Lewis, ED, Wu, D, 2018: Perspective: Should Vitamin E Recommendations for Older Adults Be Increased? Adv. Nutr. 9, 5:53-43.

Mileva, M, Galabov, AG, 2018: Vitamin E and Influenza Virus Infection Vitamin E and Influenza Virus Infection In book: Vitamin E in Hea1th and Disease, Publisher: IntechOpen, DOI: 10.5772/intechopen.80954

Miller, ER, 3rd, Pastor-Barriuso, R, Dalal, D, et al, 2005: Meta-analysis: high-dosage vitamin E supplementation may increase all-cause mortality. Ann. Intern. Med. 142:37-40.

Muñoz, SJ, Heubi, JE, Balistreri, WF, Maddrey, WC, 1989: Vitamin E deficiency in primary bil-iary cirrhosis: gastrointestinal malabsorption, frequency and relationship to other lipid-soluble vitam-ins. Hepatology 9:525-9.

Nakamura, T, Aoyama, Y, Fujita, T, Katsui, G, 1975: Studies on tocopherol derivatives: V. Intest-inal absorption of several d,1-3,4-3H2alpha-tocopheryl esters in the rat. Lipids 10:62732.

Natta, C, Machlin, L, 1972: Plasma levels of tocopherol in sickle cell anemia subjects. Am. J. Clin. Nutr. 32:1359-63.

Oski, FA, Barness, LA, 1967: Vitamin E deficiency: a previously unrecognized cause of he- molytic anemia in the premature infant. J. Pediatr. 70:211-4.

Papic, N, Pangercic, A, Vargovic, B, Vince, A, Kuzman, I, 2012: Liver involvement during influenza infection. Influenza and other Respira tory Viruses 6:2-5

Peh, HY, Tan, WS, Liao, W, Wong, S, 2016: Vitamin E therapy beyond cancer: Tocopherol versus tocotrienol. Pharmacol. Ther. 162:15269.

Rachmilewitz, EA, Shifter, A, Kahane, I, 1979: Vitamin E deficiency in beta-thalassemia major: changes in hematological and biochemical parameters after a therapeutic trial with alpha-tocopherol. Am. J. Clin. Nutr. 32:1850-6.

Ray, D, Deshmukh, P, Goswami, K, Garg, N, 2007: Antioxidant vitamin levels in sickle cell disorders. Natl. Med. J. India 20:11-6.

Rimm, EB, Stampfer, MJ, Ascherio, A, et al, 1993: Vitamin $\mathrm{E}$ consumption and the risk of coronary heart disease in men. N. Engl. J. Med. 328:1450-6.

Salonen, RM, Nyyssonen, K, Kaikkonen, J, et al, 2003: Six-year effect of combined vitamin $C$ and $\mathrm{E}$ supplementation on atherosclerotic progression: the Antioxidant Supplementation in Atherosclerosis Prevention (ASAP) Study. Circulation 107:947-50.

Serafini, M, 2000: Dietary vitamin E and T cellmediated function in the elderly: effectiveness and mechanism of action. Int. J. Dev. Neurosci. 18:401-5.

Sheppard, AJ, Pennington, JAT, Weihrauch, JL, 1980: Analysis and distribution of vitamin $E$ in vegetable oils and foods. In: Vitamin E in Health and Disease. Packer L, Fuchs J (eds). Marcel Dekker; New York, NY, USA.

Soares, KV, McGrath, JJ, 2001: Vitamin E for neuroleptic-induced tardive dyskinesia. Cochrane Database Syst. Rev.:CD000209.

Sokol, RJ, 1993: Vitamin E deficiency and neurological disorders. In: Vitamin E in Health and Disease, Packer L, Fuchs J (Eds.), Marcel Dekker, New York.

Sokol, RJ, Heubi, JE, Iannaccone, S, et al, 1983: Mechanism causing vitamin $E$ deficiency during chronic childhood cholestasis. Gastroenterology 85:1172-6.

Soltani-Frisk, S, Gronowitz, E, Andersson, H, Strandvik, B, 2001: Water-miscible tocopherol is not superior to fat-soluble preparation for vitamin E absorption in cystic fibrosis. Acta Paediatr. 90:1112-6. 
Stampfer, MJ, Rimm, EB, 1995: Epidemiologic evidence for vitamin $\mathrm{E}$ in prevention of cardiovascular disease. Am. J. Clin. Nutr. 62:S13659.

Szymańska，R, Nowicka，B, Kruk，J, 2017: Vitamin E - occurrence, biosynthesis by plants and functions in human nutrition. Mini Rev. Med. Chem. 12:1039-52.

Tabet, N, Birks, J, 2000: Vitamin E for Alzheimer's disease. Cochrane Database Syst. Rev.: CD002854.

Tasman, W, Patz, A, McNamara, JA, et al, 2006: Retinopathy of prematurity: the life of a lifetime disease. Am. J. Ophthalmol. 141:167-9.

Traber, MG, 2000: Vitamin E. In: Modern Nutrition in Health and Disease, Shils M, Olson J, Shike M, et al (Eds.), Lippincott, Philadelphia.

Traber, MG, 2007: Vitamin E regulatory mechanisms. Ann. Rev. Nutr. 27:347-62.

Traber, MG, Kayden, HJ, Green, JB, Green, MH, 1986: Absorption of water-miscible forms of vitamin $\mathrm{E}$ in a patient with cholestasis and in thoracic duct-cannulated rats. Am. J. Clin. Nutr. 44:914-8.

Traber, MG, Goldberg, I, Davidson, E, et al, 1990: Vitamin $E$ uptake by human intestinal cells during lipolysis in vitro. Gastroenterology 98:96-100.

Trevithick, JR, Robertson, JM, Mitton, KP, 1993: Vitamin $E$ and the eye. In: Vitamin $E$ in
Health and Disease, Packer, L, Fuchs, J (Eds.), Marcel Dekker, New York.

Vivekananthan, DP, Penn, MS, Sapp, SK, et al, 2003: Use of antioxidant vitamins for the prevention of cardiovascular disease: Meta-analysis of randomised trials. Lancet 361:2017-20.

Walter, PB, Fung, EB, Killilea, DW, et al, 2006: Oxidative stress and inflammation in ironoverloaded patients with beta-thalassaemia or sickle cell disease. Br. J. Haematol. 135:254-7.

Wang, T, Xu, L, 2019: Circulating vitamin E levels and risk of coronary artery disease and myocardial infarction: A mendelian randomization study. Nutrients Sept. 9;11(9). pii: E 2153. WHO, 2010: Report on Global Surveillance of Epidemic-prone Infectious Diseases. WHO/CsR/ ISR/ Available from: http://www. who. int/emc Wolf, G, 2006: How an increased intake of alpha-tocopherol can suppress the bioavailability of gamma-tocopherol. Nutr. Rev. 64:295-9.

Taubenberger, J, Morens, DM, 2008: The pathgology of influenza virus infection. Ann. Rev. Pathol. 3:499-522.

Yoshida, H, Yusin, M, Ren, I, et al, 1992: Identification, purification, and immunochemical characterization of a tocopherol-binding protein in rat liver cytosol. J. Lipid Res.33:343-6.

Zingg, JM, Azzi, A, 2004: Non-antioxidant activities of vitamin E. Curr. Med. Chem. 11:11138.

Table 1: Water-soluble and fat-soluble vitamins
\begin{tabular}{|l|l|l|}
\hline Vitamins & Function & Deficiency syndrome \\
\hline Water-soluble & Thiamine pyrophosphate & Beriberi \\
\hline B1, thiamine & Flavine adenine dinucleotide & \\
\hline B2, riboflavin & Nicotinamide adenine dinucleotide & Pellagra \\
\hline Niacin, nicotinic acid & Transaminase cofactor & Anemia \\
\hline B6, pyroxidine, pyridoxa & One carbon transfer & Pernicious anemia \\
\hline B12, cobalamin & One carbon transfer & Megaloblastic anemia \\
\hline Folate & Pyruvate carboxlase cofactor & \\
\hline Biotin & Coenzyme A & \\
\hline Pantothenate & Antioxidant, collagen synthesis & Scurvy \\
\hline C ascorbate & & Xerophthalmia \\
\hline Fat-soluble & Vision, epithelial differentiation & \\
\hline A & & \\
\hline Retinol & & \\
\hline Retinal & & Rickets, osteomalacia \\
\hline Retinoic acid & Prohormone for calcium regulation & \\
\hline D & & \\
\hline Cholecalciferol & & \\
\hline Ergocalciferol & Antioxidant & \\
\hline E & & \\
\hline Tocopherols & Clotting factors, bone proteins & \\
\hline K & & Hemorrhagic disease \\
\hline Phylloquinone & & \\
\hline Menaquinone & & \\
\hline Menadione & & \\
\hline
\end{tabular}

